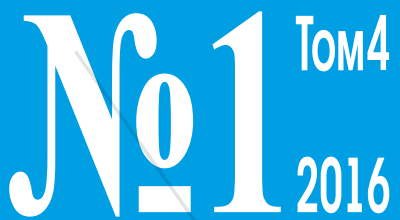

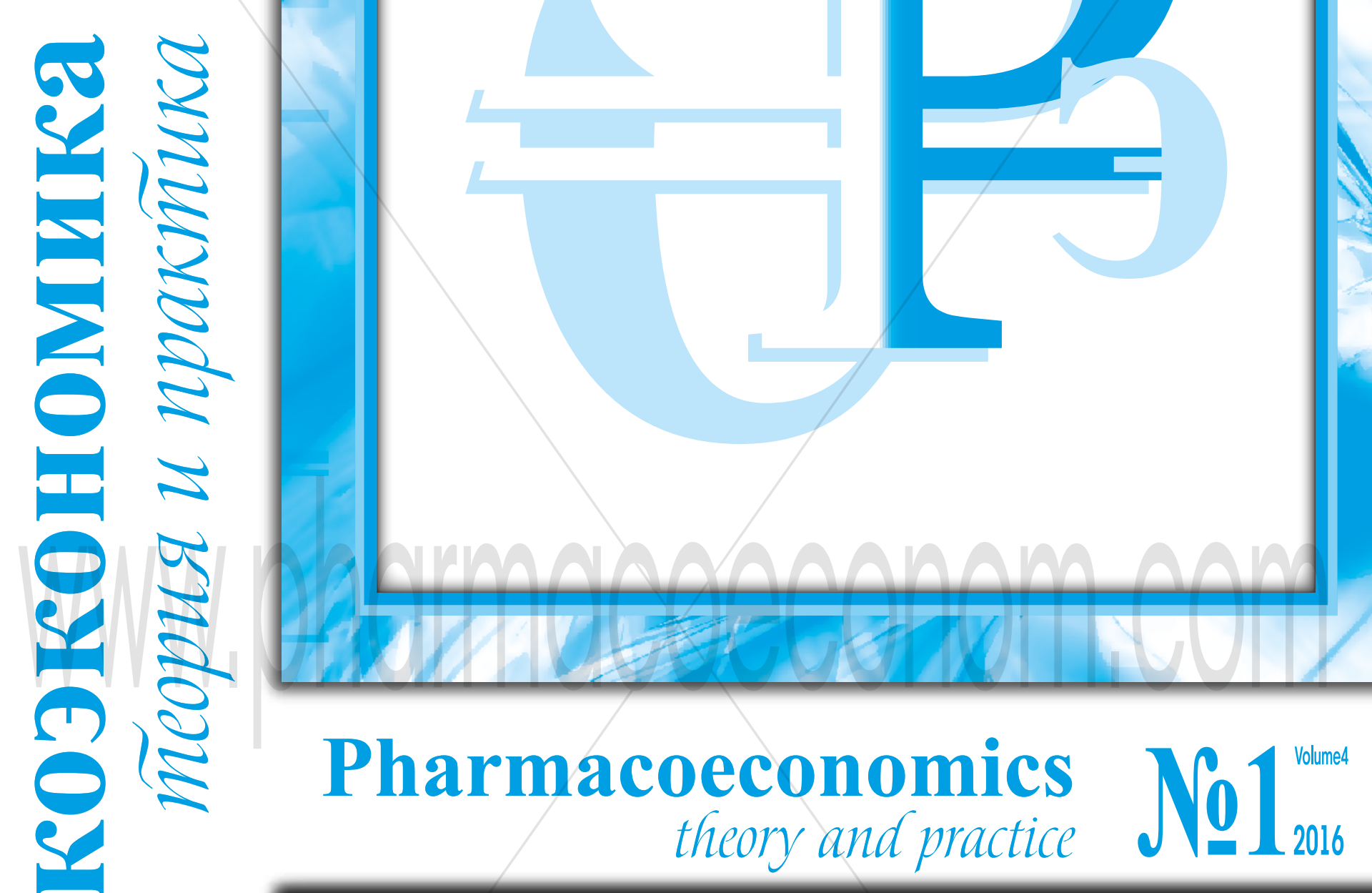

$\square$ МЕТОДОЛОГИЧЕСКИЕ ОСНОВЫ ФАРМАКОЭКОНОМИЧЕСКОГО МОДЕЛИРОВАНИЯ

$\square$ РЕЗУЛЬТАТЫ РОССИЙСКИХ ФАРМАКОЭКОНОМИЧЕСКИХ ИССЛЕДОВАНИЙ

口 МАТЕРИАЛЫ Х НАЦИОНАЛЬНОГО КОНГРЕССА С МЕЖДУНАРОДНЫМ УЧАСТИЕМ «РАЗВИТИЕ ФАРМАКОЭКОНОМИКИ И ФАРМАКОЭПИДЕМИОЛОГИИ В РОССИЙСКОЙ ФЕДЕРАЦИИ» 4-5 апреля 2016 г., г. Нижний Новгород 


\section{ФАРМАКОЭКОНОМИЧЕСКАЯ ОЦЕНКА ПРИМЕНЕНИЯ АБАТАЦЕПТА У ПАЦИЕНТОВ С РЕВМАТОИДНЫМ АРТРИТОМ, ИМЕЮЩИХ НЕДОСТАТОЧНЫЙ ОТВЕТ НА ТЕРАПИЮ МЕТОТРЕКСАТОМ,} В РОССИЙСКОЙ ФЕДЕРАЦИИ

Куликов А.Ю., Почуприна А.А. ГБОУ ВПО «Первый МГМУ им. И.М. Сеченова» Минздрава РФ, Москва

Резюме: Была проведена адаптация шотландской фрармакоэкономической модели, на основе которой проводилась оценка применения подкожной и внутривенной форм абатацепта в сравнении с другими генно-инженерными биологическими препаратами (ГИБП): инфликсимаб, адалимумаб, тоцилизумаб, этанерцепт, голимумаб и цертолизумаба пэгол, имеющими доказанную эффрективность у пациентов с недостаточным ответом на терапию метотрексатом. В качестве основного метода исследования был использован анализ «минимизации затрат». Временной горизонт составил 3 года, коэфффициент дисконтирования - 3,5\%.

Прямые затраты на лечение абатацептом подкожной формы составили 2 546448 руб. в течение 3-х лет и были ниже затрат, требуемых на лечение тоцилизумабом, адалимумабом, голимумабом, инфликсимабом и цертолизумабом. В рамках установленного бюджета данная экономия денежных средств позволяет пролечить дополнительных пациентов. В частности, применение п/к формы абатацепта по сравнению с вышеуказанными ГИБП позволит в течение 3-х лет обеспечить терапией РА от 7 до 37 пациентов в дополнение к 100 пациентам.

В то же время абатацепт внутривенной формы является одним из наиболее экономически выгодных препаратов в группе ГИБП и позволяет экономить от 49,6 тыс. руб. до 1560 тыс. руб. в течение 3-х лет терапии из расчета на одного пациента с недостаточным ответом на лечение метотрексатом. При этом выбор в/в формы абатацепта по сравнению с другими ГИБП (за исключением этанерцепта) позволит пролечить в течение 3-х лет от 40 до 80 пациентов в дополнение к 100 пациентам.

Таким образом, лечение абатацептом в/в и п/к формы можно считать целесообразным у пациентов с выявленной недостаточной эфффективностью терапии МТ с точки зрения фармакоэкономического анализа.

Ключевые слова: ревматоидный артрит, абатацепт, тоцилизумаб, инфрликсимаб, голимумаб, адалимумаб, цертолизумаба пэгол, метотрексат, генно-инженерные биологические препараты, непрямое сравнение, анализ «минимизации затрат».

\section{Введение:}

Ревматоидный артрит (РА) занимает одно из ведущих мест среди ревматических заболеваний по распространённости и по затратам на лечение. РА представляет собой хроническое воспалительное аутоиммунное заболевание, преимущественно поражающее ткани суставов с возможным вовлечением в патологическое воспаление внутренних органов и приводит к необратимым повреждениям суставов [7, 8, 9]. Дальнейшее прогрессирование деструкции способствует инвалидизации и потере трудоспособности пациентов, которые могут наблюдаться у 2/3 больных РА уже на 10-ом году заболевания [3, 10]. Стоит отметить, что развитие РА у пациентов начинается в возрасте 35-60 лет, затрагивая при этом наиболее трудоспособную группу населения, что определяет данное заболевание, как социально-экономическую проблему для всего общества [1]. Социально-экономическое бремя ревматоидного артрита в Российской Федерации в 2011 году составило 8009,9 млн. руб. [32]. При этом 73\% в структуре социально-экономического бремени составляли косвенные издержки от стойкой нетрудоспособности по причине инвалидизации, в то время как медицинские издержки на лекарственное обеспечение, оказание стационарной, амбулаторной и скорой помощи составляли только $16,1 \%$ [32].

Современная терапия РА направлена на два пути развития заболевания: контроль над иммунным ответом и снижение образования медиаторов воспаления. На данный момент согласно клиническим рекомендациям Ассоциации ревматологов России (АРP) [10] по лечению пациентов с РА выделяют четыре основные группы препаратов:

1. Нестероидные противовоспалительные препараты (НПВП);

2. Глюкокортикостериоиды (ГК);

3. Базисные противовоспалительные препараты (БПВП);

4. Генно-инженерные биологические препараты (ГИБП) [10].

Препараты групп НПВП и ГК относятся к симптоматической терапии, кроме того, их применение ограничено в связи с высоким риском возникновения нежелательных явлений. Для контроля над заболеванием в качестве базисной терапии пациентам рекомендуют использовать метотрексат (МТ), который относится к группе БПВП и является «золотым стандартом» в лечении РА [4]. Однако у 50-60 \% пациентов, применяющих БПВП, наблюдается недостаточный ответ на терапию [5], и только после разработки ГИБП такие пациенты получили возможность эфффективного лечения РА.

Группа ГИБП появилась сравнительно недавно, но в распоряжении врачей-ревматологов уже находится достаточно данных клинических исследований, чтобы судить об эфффективности применения этой группы препаратов у пациентов с РА. ГИБП способны подавлять воспаление, снижать прогрессирование деструкции суставов, позволяют снизить риск развития коморбидных заболеваний, а также достичь главных целей терапии: снижения активности РА, наступления клинической ремиссии и увеличения продолжительности жизни пациентов $[7,8,10]$.

Основная часть группы ГИБП представлена ингибиторами фрактора некроза опухоли альфа $\left(Ф \mathrm{HO}_{\mathrm{a}}\right)$, такими как: инфрликсимаб, адалимумаб, этанерцепт и цертолизумаба пэгол. Кроме ингибиторов ФНО ${ }_{\alpha}$ к ГИБП относятся препараты с иным механизмом действия. К таким лекарственным 
средствам относится абатацепт - единственный препарат, выступающий в качестве блокатора стимуляции Т-лимфоцитов, и тоцилизумаб - блокатор рецепторов интерлейкина-6 [7, 9, 10]. В частности, абатацепт за счет избирательного подавления костимуляции Т-лимфоцитов способствует уменьшению продукции провоспалительных цитокинов и аутоантител, позволяя ингибировать аутоиммунный процесс на самом раннем этапе патогенеза РА, блокируя порочный круг аутоиммунного воспаления и препятствуя прогрессированию заболевания [36].

Большинство ГИБП включены в Перечень жизненно важных и необходимых лекарственных препаратов (ЖНВЛП). По состоянию на 1 марта 2016 года предельные цены зарегистрированы для следующих препаратов: абатацепт (п/к и в/в формы), адалимумаб, инфликсимаб, тоцилизумаб, цертолизумаба пэгол и этанерцепт [24,35].

В условиях ограниченности ресурсов здравоохранения и относительно высокой стоимости ГИБП, представляющих собой инновационные препараты, принятие решений о рациональности обеспечения пациентов указанными препаратами за счет бюджетных средств должно быть обосновано [12]. Одним из важных инструментов для выбора наиболее приемлемой терапии является фармакоэкономическая оценка. В связи с чем проведение фармакоэкономического исследования различных ГИБП представляется актуальным для Российской системы здравоохранения.

\section{Цель исследования:}

Провести адаптацию к условиям российской системы здравоохранения зарубежной фармакоэкономической модели применения абатацепта подкожной (п/к) и внутривенной (в/в) фрорм у пациентов с РА, имеющих неадекватный ответ на терапию метотрексатом.

\section{Материалы и методы исследования:}

В исследовании была использована шотландская фармакоэкономическая модель, разработанная Mapi Consultancy (www.mapi-consultancy. com), и адаптированная к условиям российской системы здравоохранения. Данное исследование имело ретроспективный дизайн и было проведено с использованием следующих методов: анализа эффективности, анализа затрат, анализа «минимизации затрат», анализа «упущенных возможностей» и анализа чувствительности.

Анализ эффективности, позволяющий сравнить альтернативные виды терапии РА, был осуществлен на основе результатов сетевого мета-анализа, проведенного Janssen K.J. et al., в который были включены только рандомизированные клинические исследования, определяющие эффективность и безопасность ГИБП по строго заданным критериям и имеющие сопоставимый период наблюдения [18, 19].

Расчет прямых медицинских затрат является преимущественным с точки зрения системы здравоохранения. В данном исследовании были учтены прямые медицинские затраты на лечение РА, а именно: затраты на лекарственную терапию, затраты на введение и мониторинг. Стоимость терапии лекарственными препаратами на исследуемый период времени (t) была рассчитана с учетом следующей формулы (1):

$$
\text { Cost } P(t)=\text { Price } \times N \times F \text {, где (1) }
$$

$\operatorname{Cost} P(t)$ - затраты на терапию лекарственным препаратом $(P)$ в течение исследуемого времени $(t)$, руб.;

Price - стоимость 1 фрл. лекарственного препарата $(P)$, руб.;

$N$ - число фрлаконов лекарственного препарата $(P)$, требуемое на одно введение;

$F$ - число введений лекарственного препарата $(P)$, требуемое в течение исследуемого времени $(t)$.

В ходе расчета затрат на фармакотерапию были учтены средние тендерные цены на исследуемые препараты за период с 1 января 2015 года по 31 декабря 2015 года (база данных «Мониторинг тендерных закупок» информационно-аналитической системы «Headway Company») по Moсковскому региону. При анализе закупок в указанный период времени не были обнаружены тендеры на закупку тоцилизумаба с дозировкой 400 мг. Таким образом, для расчета средней тендерной цены на тоцилизумаб 400 мг были учтены данные за 2014 год. Выбор уровня средних тендерных цен представляется наиболее применимым, так как показывает реальную практику государственных закупок ГИБП. Кроме того, для препаратов, входящих в перечень ЖНВЛП, были проведены дополнительные расчеты с учетом зарегистрированных предельных отпускных цен производителей $[24,35]$. Число введений и число флаконов на прием в течение исследуемого времени были рассчитаны в соответствии с инструкцией по медицинскому применению [25-31].
В адаптированной модели временной горизонт исследования составляет 3 года. Выбор горизонта исследования менее 10 лет был связан с постоянно появляющимися новыми технологиями и методами лечения. Кроме того, долгосрочные данные о лечении пациентов с помощью сравниваемых в исследовании препаратов отсутствуют. В подтверждение рациональности выбора горизонта исследования менее 10 лет можно также указать тот факт, что большинство экономических исследований, посвященных лечению пациентов с РА, имели такой же горизонт исследования. Важно добавить, что международная исследовательская организация OMERACT (Outcome Measures in Rheumatoid Arthritis Clinical Trials - оценка исходов ревматоидного артрита в клинических исследованиях) также рекомендует устанавливать короткий горизонт исследования $[13,14,17,20,21,22,23]$.

Сравнение альтернативных методов лечения проводили с помощью анализа «минимизации затрат» при использовании формулы (2) путем последовательного сравнения затрат на лечение в/в и п/к форм абатацепта с другими препаратами из группы ГИБП.

$$
\text { CMA }=\text { Costs } 1-\text { Costs2, где (2) }
$$

CMA - разница затрат сравниваемых видов терапий, руб.;

Costs1 - совокупность затрат при лечении 1-ой схемой терапии, руб.; Costs2 - совокупность затрат при лечении 2-ой схемой терапии, руб. [12].

Для оценки возможности рационального использования бюджета был проведен анализ «упущенных возможностей» с учетом фрормулы (3):

$$
Q=E / \text { Costs }_{\text {low }} \text {, где (3) }
$$

$Q$ - результат анализа «упущенных возможностей», число дополнительно пролеченных пациентов;

$E$ - возможная экономия при переходе с более затратной терапии на менее затратную, руб.;

Costs $_{\text {low }}$ - совокупность затрат при лечении менее затратной терапией, руб. [6].

\section{Результаты и обсуждение}

\section{Анализ эффективности}

Анализ эффеективности подкожной формы абатацепта в отношении альтернативных видов лечения был основан на непрямом сравнении препаратов группы ГИБП в рамках сетевого мета-анализа, проведенноro Janssen K.J. et al. [18]. В анализ были включены рандомизированные клинические исследования, найденные в результате систематического обзора литературы за период с 1990 по 2012 гг. Для сравнения были использованы следующие конечные точки эффективности: изменение показателя состояния здоровья $\mathrm{HAQ}$ CFB (Health Assessment Questionnaire Change From Baseline), частота ответа на лечение по критериям ACR 20, 50, 70 (American College of Rheumatology 20, 50, 70), частота ремиссии DAS28 (Disease Activity Score based on 28 Joints). В исследование были так же включены конечные точки безопасности и переносимости: частота развития серьезных нежелательных явлений (СНЯ), возникновения инфекций или серьезных инфекций, выбывания из исследования по любой причине или по причине неэффективности лечения. Схема взаимосвязи исследований представлена на рисунке 1 в виде сети доказательств [18, 19]. Согласно представленным данным в ходе мета-анализа также было проведено сравнение с анакинрой - препаратом, не зарегистрированным на территории России по состоянию на 1 марта 2016 года, в связи с чем сравнение с анакинрой в рамках данного исследования не проводилось $[18,19,24]$.

На основе результатов выбранных клинических исследований была проведена сравнительная оценка эффективности по указанным выше критериям. На рисунке 2 графически продемонстрировано распределение отношения шансов (ОШ) для частоты достижения ответа на лечение по критериям ACR 20/50/70 при сравнении абатацепта п/к формы с другими ГИБП. Данное распределение указывает на отсутствие статистически значимых различий в эффективности по указанным критериям через 6 и 12 месяцев терапии между п/к формой абатацепта и этанерцептом, голимумабом, инфликсимабом, адалимумабом, тоцилизумабом, а также в/в формой абатацепта [19]. Единственным статистически значимым различием было увеличение частоты ответа на лечение по критерию ACR 20 через 6 месяцев терапии при применении цертолизумаба пэгол по сравнению с абатацептом п/к, однако, данное различие не наблюдалось 


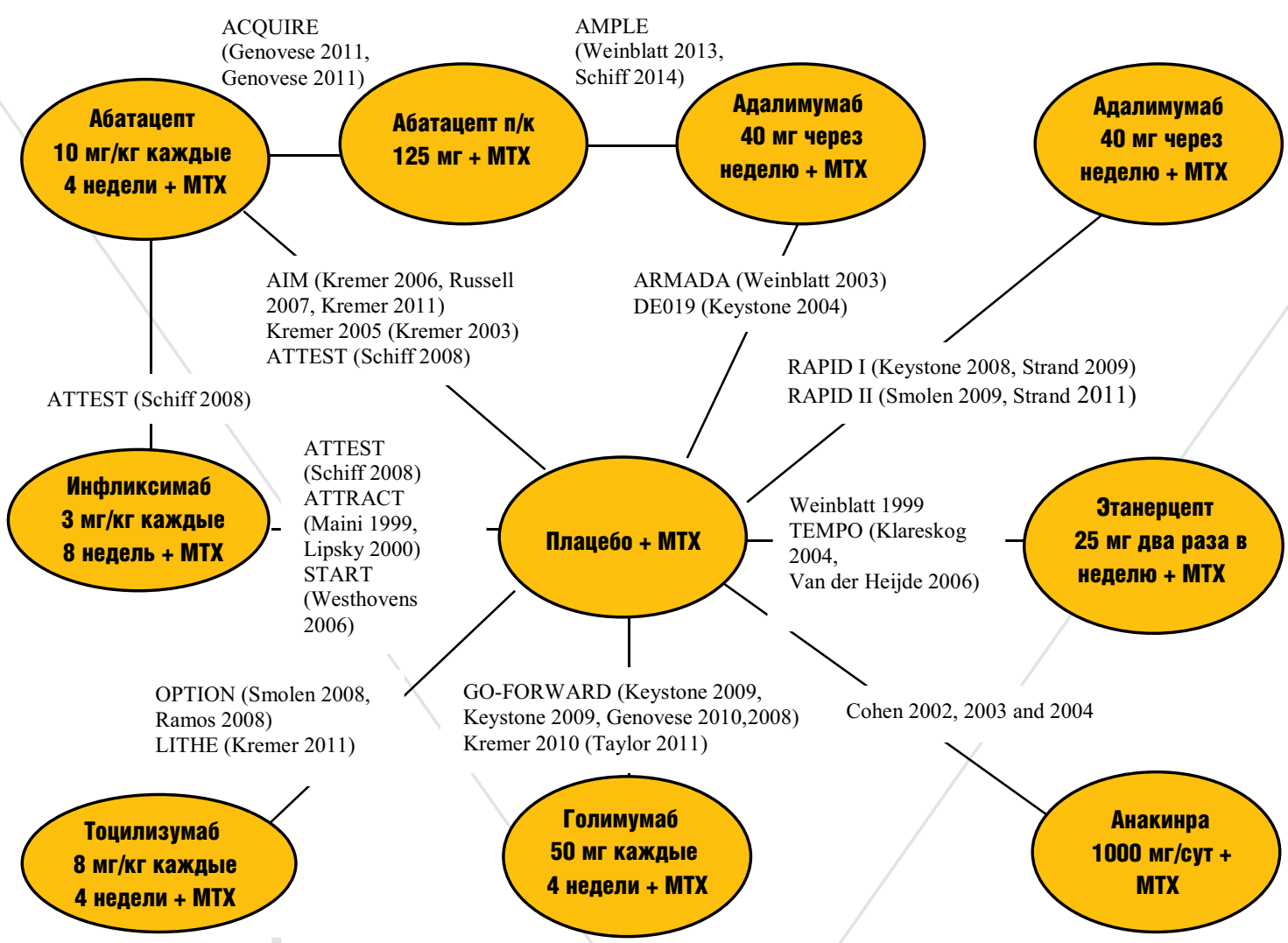

Рисунок 1. Диаграмма сети доказательств (адаптировано из [18], ссылки на полнотекстовые статьи см. в [18])
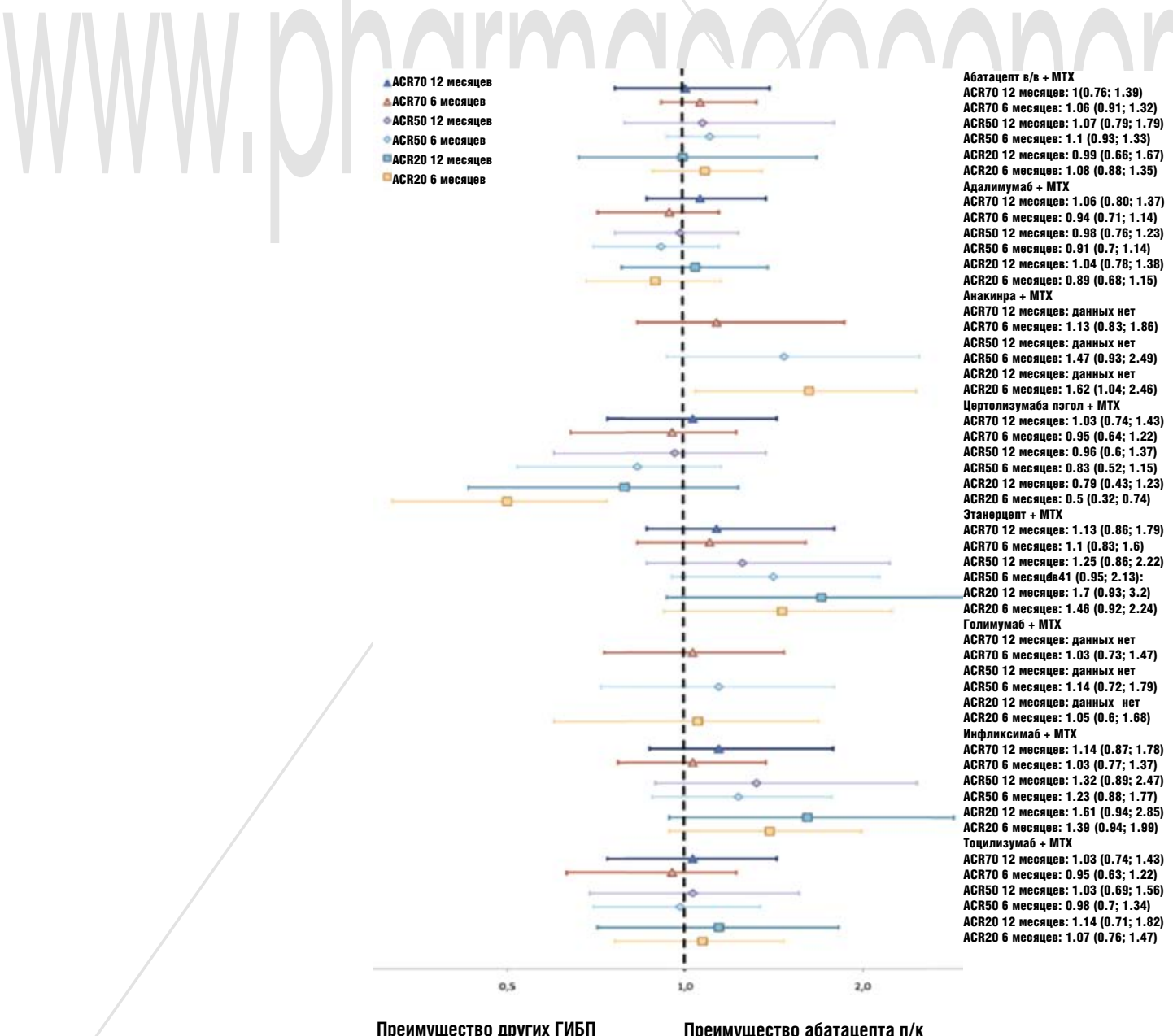

Рисунок 2. Относительная эффективность абатацепта п/к по сравнению с другими ГИБП (ОШ) по частоте ответа на лечение по критериям ACR через 6 и 12 месяцев терапии (адаптировано из [18]) 
через 12 месяцев терапии. Кроме того, результаты сетевого мета-анализа показали, что абатацепт п/к форма, скорее всего, обладает сопоставимой со всеми другими ГИБП эффрективностью в отношении показателей $\mathrm{HAQ}$ CFB, DAS28 и безопасностью.

Результаты ранее опубликованных мета-анализов также позволяют предположить, что внутривенная форма абатацепта по сравнению с другими ГИБП имеет сопоставимую эффективность в отношении изменения индекса HAQ CFB через 6 и 12 месяцев терапии, частоты ответа на лечение по критерию ACR 50 через 6 и 12 месяцев терапии (за исключением цертолизумаба пэгол через 12 месяцев терапии), частоты ответа на лечение по критерию ACR 70 через 6 месяцев терапии [30, 34].

C учетом допущения о сопоставимой эфффективности как подкожной, так и внутривенной форм абатацепта с другими препаратами группы ГИБП наиболее приемлемым методом для фармакоэкономической оценки применения абатацепта у пациентов с РА является метод анализа «минимизации затрат» $[11,16]$.

\section{Анализ затрат}

Следующим этапом проведения фармакоэкономической оценки был анализ затрат на лечение пациентов с РА, требующих на фоне недостаточного ответа на терапию МТ назначения препаратов группы ГИБП. В данной модели были учтены только прямые затраты: стоимость фармакотерапии, затраты на введение препаратов, а также стоимость лабораторных тестов, требующихся для мониторинга состояния пациента в процессе лечения. Временной горизонт был установлен на 3-хлетний период. Процент дисконтирования был установлен на уровне $3,5 \%$.

Затраты на фрармакотерапию рассчитывались согласно режиму дозирования, прописанному в инструкции по медицинскому применению. Для препаратов, требующих дозирования по массе тела (инфликсимаб, тоцилизумаб и абатацепт в/в), средний вес пациентов с РА был принят за 70 кг. Суммарные трехлетние затраты на фрармакотерапию представлены в таблице 1.

Таблица 1. Затраты на фрармакотерапию при использовании 3-летнего горизонта исследования из расчета на 1 пациента

\begin{tabular}{|c|c|c|}
\hline \multicolumn{3}{|c|}{ Затраты на фармакотерапию } \\
\hline $\mathrm{MHH}(\mathrm{TH})$ & $\begin{array}{c}\text { С учетом средних } \\
\text { тендерных цен, руб. }\end{array}$ & $\begin{array}{c}\text { С учетом цен } \\
\text { ЖНВЛП (включая } \\
\text { 10\% НДС), руб. }\end{array}$ \\
\hline Абатацепт п/к (Оренсия $\left.{ }^{\circledast}\right)$ & 2540487 & 2309534 \\
\hline Абатацепт в/в (Оренсия $\left.{ }^{\circledR}\right)$ & 1930148 & 1808300 \\
\hline Этанерцепт (Энбрел ${ }^{\circledR}$ ) & 1983747 & 1790083 \\
\hline Адалимумаб (Хумира $\left.{ }^{\circledR}\right)$ & 2924350 & 2824026 \\
\hline Инфрликсимаб (Ремикейд $\left.{ }^{\circledast}\right)$ & 3228671 & 3034509 \\
\hline Тоцилизумаб (Актемра $\left.{ }^{\circledR}\right)$ & 3485199 & 3216870 \\
\hline $\begin{array}{c}\text { Цертолизумаба пэгол } \\
\left.\text { (Симзия }{ }^{\circledR}\right)\end{array}$ & 2721667 & 2262637 \\
\hline Голимумаб (Симпони $\left.{ }^{\circledast}\right)$ & 3145887 & $\begin{array}{c}\text { Цена не } \\
\text { зарегистрирована }\end{array}$ \\
\hline
\end{tabular}

Как видно из таблицы 1, наибольшие затраты на фармакотерапию характерны для тоцилизумаба, инфликсимаба, голимумаба и адалимумаба. Наименьшие затраты на фармакотерапию характерны для этанерцепта и абатацепта в/в. Важно отметить, что модель не учитывает затраты на сопутствующую терапию MT, так как при проведении анализа «минимизации затрат», данные расходы нивелируются и не влияют на конечный результат анализа.

Из представленных в таблице 1 данных также видно, что с учетом зарегистрированных предельных отпускных цен ЖНВЛП абатацепт п/к по-прежнему занимает четвертое место по уровню затрат на фрармакотерапию, а в/в форма абатацепта наравне с этанерцептом по-прежнему являются наиболее экономичными препаратами среди ГИБП. Дальнейшие расчеты были проведены с учетом средних тендерных цен на препараты.

Следующим этапом фрармакоэкономического анализа был расчет затрат на введение препаратов. В данную статью расходов были включены стоимость расходных материалов при проведении п/к и в/в введения, стоимость работы медсестры в случае применения препаратов, требующих длительного внутривенного введения, таких как: инфрликсимаб (2 часа), тоцилизумаб (1 час) и абатацепт в/в (30 минут) $[25,26,27]$. Следует отметить, что в модели вероятность введения внутривенных препаратов в дневном или круглосуточном стационаре составляла $50 \%$.

Совокупность затрат на введение препаратов в течение 3-х лет терапии представлена в таблице 2. Очевидно, что высокий уровень затрат на введение характерен для внутривенных форм препаратов (инфрликсимаба, тоцилизумаба, абатацепта), а низкий уровень затрат - для подкожных лекарственных форм препаратов.

Таблица 2. Затраты на введение при использовании 3-летнего горизонта исследования из расчета на одного пациента с РА

\begin{tabular}{|c|c|c|}
\hline \multicolumn{3}{|c|}{ Затраты на введение и мониторинг } \\
\hline MHH & $\begin{array}{c}\text { Затраты на введение, } \\
\text { руб. }\end{array}$ & $\begin{array}{c}\text { Затраты на мониторинг*, } \\
\text { руб. }\end{array}$ \\
\hline $\begin{array}{c}\text { Абатацепт п/к } \\
\left.\text { (Оренсия }{ }^{\circledR}\right)\end{array}$ & 5820 & 141 \\
\hline $\begin{array}{l}\text { Абатацепт в/в } \\
\left.\text { (Оренсия }{ }^{\circledR}\right)\end{array}$ & 9764 & 141 \\
\hline $\begin{array}{l}\text { Этанерцепт } \\
\left.\text { (Энбрел }{ }^{\circledast}\right)\end{array}$ & 5820 & 160 \\
\hline $\begin{array}{c}\text { Адалимумаб } \\
\left(\text { Хумира }^{\circledR}\right)\end{array}$ & 2910 & 141 \\
\hline $\begin{array}{l}\text { Инфликсимаб } \\
\left.\text { (Ремикейд }{ }^{\circledast}\right)\end{array}$ & 14659 & 141 \\
\hline $\begin{array}{l}\text { Тоцилизумаб } \\
\text { (Актемра }^{\circledR} \text { ) }\end{array}$ & 14357 & 1079 \\
\hline $\begin{array}{l}\text { Цертолизумаба } \\
\text { пэгол (Симзия) }\end{array}$ & 3064 & 141 \\
\hline $\begin{array}{l}\text { Голимумаб } \\
\text { (Симпони }^{\circledR} \text { ) }\end{array}$ & 1339 & 141 \\
\hline
\end{tabular}

*Затраты на мониторинг рассчитывались только для первых 3-х месяцев терапии

Далее были рассчитаны затраты на лабораторные тесты, необходимые для мониторинга состояния здоровья пациентов до начала и в течение приема ГИБП (Таблица 2). Информация о требуемых тестах и частоте их проведения была взята из инструкций по медицинскому применению изучаемых препаратов. Согласно данным инструкций основными требованиями для начала терапии ГИБП является диагностика туберкулеза и гепатита В у пациентов С РА, а также необходим мониторинг состояния пациента по данным параметрам в течение первых трех месяцев терапии [25,26,27]. Далее мониторинг состояния пациента проводится по рекомендации врача, и модель включает допущение об одинаковой частоте лабораторных тестов при дальнейшем лечении пациентов с PA вследствие сопоставимой эфффективности сравниваемых ГИБП $[18,19]$. Таким образом, затраты на мониторинг после 3-х месяцев терапии не учитывались в модели.

Сравнение затрат на мониторинг среди группы ГИБП показало, что наибольшие расходы на мониторинг наблюдаются при применении тоцилизумаба, что связано с необходимостью контроля уровня нейтросрилов, тромбоцитов, а также функции печени при использовании данного препарата (таблица 2).

При суммировании расходов на фрармакотерапию, введение и лабораторные тесты нами были получены общие затраты на лечение одного пациента с РА в течение 3-летнего горизонта исследования, результаты представлены на рисунке 3. Очевидно, что в структуре суммарных затрат на лечение ГИБП пациентов с РА наибольшая доля расходов приходится на закупку лекарственных препаратов.

Таким образом, наиболее высокий уровень расходов на лечение характерен для тоцилизумаба, инфрликсимаба, голимумаба и адалимумаба. Абатацепт п/к занимает шестое место по уровню суммарных затрат среди препаратов группы ГИБП, уступая абатацепту в/в и этанерцепту.

\section{Анализ «минимизации затрат»}

На следующем этапе была проведена фармакоэкономическая оценка применения абатацепта п/к у пациентов с РА, не отвечающих на терапию метотрексатом, методом «минимизации затрат». Результат анализа 
Затраты на лечение при использовании горизонта исследования в 3 года

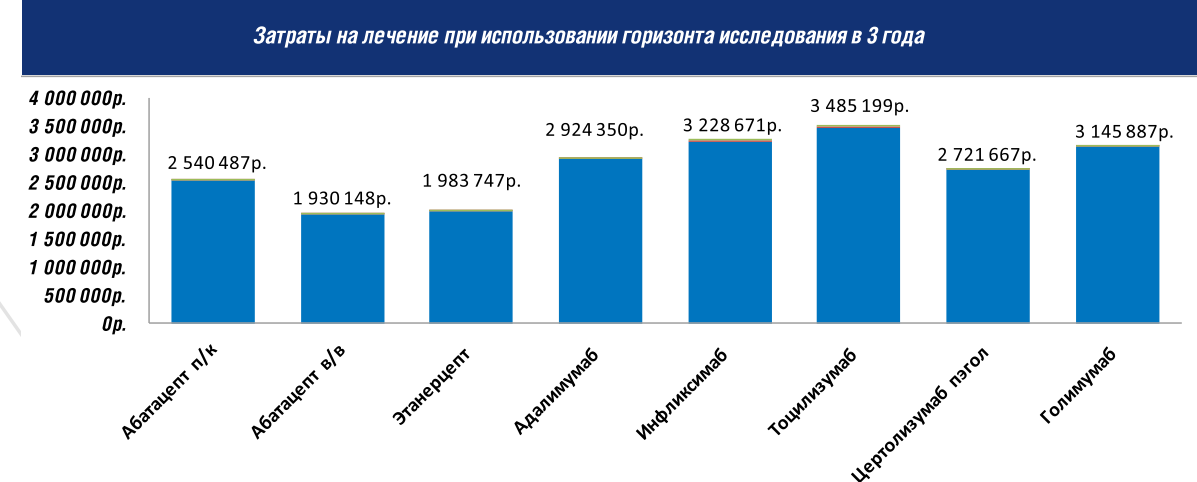

Рисунок 3. Суммарные затраты на лечение одного пациента в течение 3-х лет

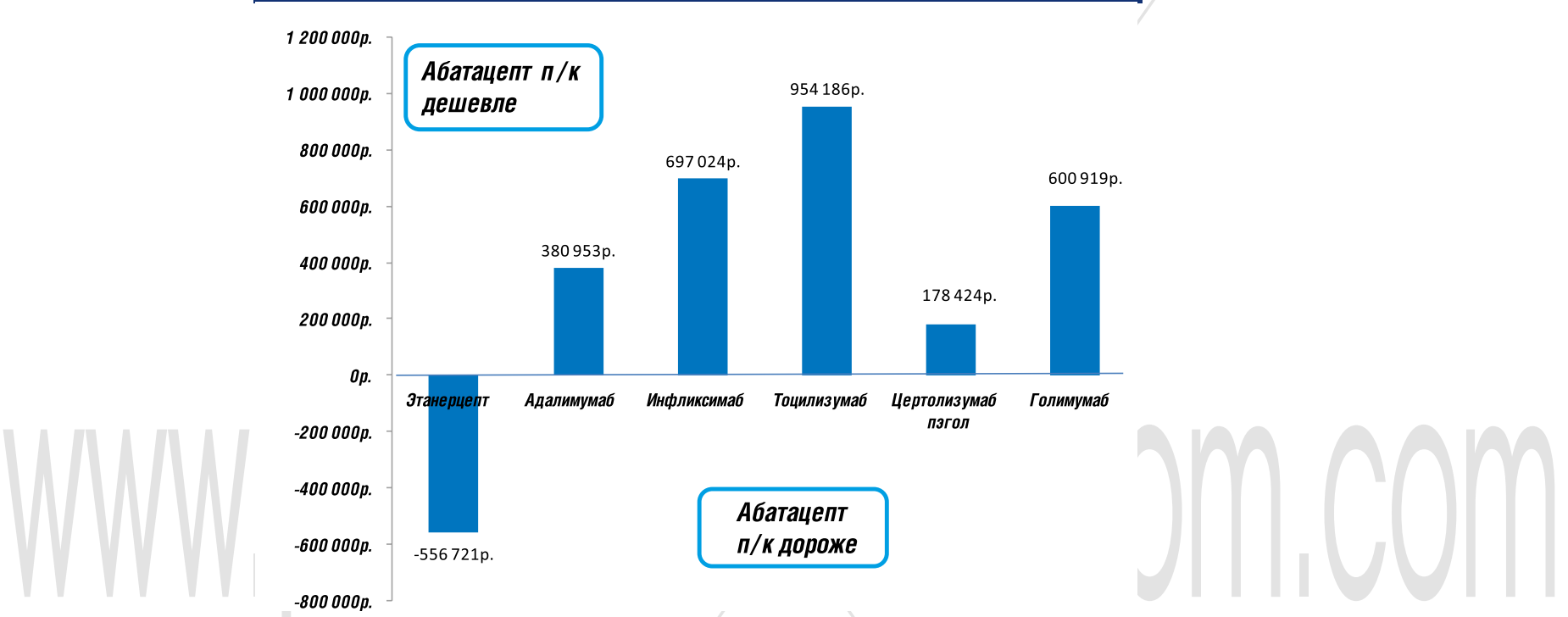

Рисунок 4. Разница в общих затратах (из расчета на 1 пациента за 3 года терапии) на лечение альтернативными препаратами в сравнении с абатацептом п/к

определяли, как разницу в суммарных затратах на лечение между абатацептом п/к и каждым из альтернативных ГИБП.

Согласно данным, представленным на рисунке 4, можно увидеть, что при выборе абатацепта п/к в качестве препарата для лечения РА у паци- ентов, не отвечающих на терапию метотрексатом, наблюдается экономия денежных средств по сравнению с такими препаратами, как адалимумаб, инфликсимаб, тоцилизумаб, цертолизумаба пэгол и голимумаб.

Параллельно был проведен расчет экономии средств при применении в/в формы абатацепта. Данные представлены на рисунке 5.

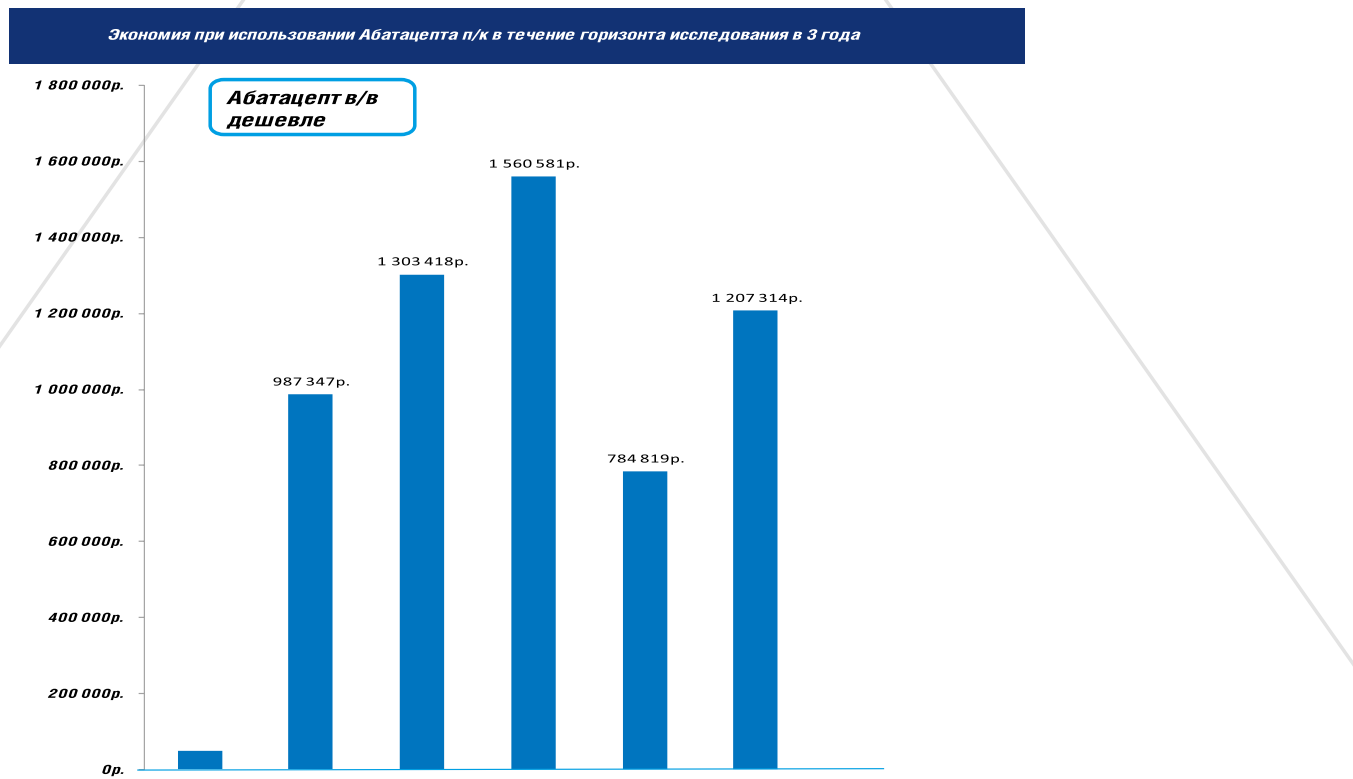

Рисунок 5. Разница в общих затратах (из расчета на 1 пациента за 3 года терапии) на лечение альтернативными препаратами в сравнении с абатацептом в/в 
Абатацепт в/в способствует экономии денежных средств по сравнению с применением адалимумаба, тоцилизумаба, инфликсимаба, цертолизумаба пэгол и голимумаба и этанерцепта. Таким образом, в/в форма абатацепта представляет собой одну из наименее затратных альтернатив среди всех применяемых ГИБП.

\section{Анализ «упущенных возможностей»}

Для оценки рационального использования бюджетных средств был проведен анализ «упущенных возможностей», результаты которого показали, что для симулируемой когорты в 100 пациентов с РА, не отвечающих на терапию метотрексатом, применение абатацепта п/к фрормы позволит дополнительно пролечить 14 пациентов в течение 3-х лет по сравнению с адалимумабом, 23 пациента по сравнению с голимумабом, 27 пациентов по сравнению с инфликсимабом, 37 пациентов по сравнению с тоцилизумабом и 7 пациентов по сравнению с цертолизумабом. В тоже время выбор абатацепта в/в формы в качестве препарата для лечения РА позволит обеспечить терапию в течение 3-х лет еще 50 пациентам по сравнению с адалимумабом, 67 пациентам по сравнению с инфликсимабом, 80 пациентам по сравнению с тоцилизумабом, 40 пациентам по сравнению с цертолизумабом пэгол и 62 пациентам по сравнению с голимумабом.

\section{Анализ чувствительности}

В ходе проверки стабильности полученных результатов был проведен однофакторный анализ чувствительности. В качестве изменяемого и наиболее влияющего на устойчивость результатов фактора была выбрана цена на препараты ГИБП. На рисунках 6 и 7 приведены результаты анализа чувствительности, демонстрирующие максимальный процент увеличения цены на абатацепт, при котором сохраняется экономия бюджетных средств при применении абатацепта по сравнению с другими ГИБП.
Проведенный анализ чувствительности показал стабильность экономии бюджетных средств при выборе как в/в, так и п/к форм абатацепта в рамках адапатированной фармакоэкономической модели.

\section{Заключение:}

В ходе настоящего фармакоэкономического исследования было проведено сравнение прямых медицинских затрат на лечение пациентов с РА, имеющих в анамнезе недостаточную эффективность терапии метотрексатом, препаратом абатацепт по сравнению с другими ГИБП (этанерцепт, тоцилизумаб, голимумаб, цертолизумаба пэгол, адалимумаб). В расчет прямых медицинских затрат были включены затраты на лекарственную терапию, на введение препаратов и лабораторный мониторинг.

По результатам анализа «минимизации затрат» в/в форма абатацепта является сопоставимой с этанерцептом и наиболее экономически выгодной по сравнению со всеми остальными ГИБП, позволяя экономить от 49 тыс. руб. (по сравнению с этанерцептом пэгол) до 1560 тыс. руб. (по сравнению с тоцилизумабом) в течение 3-х лет терапии из расчета на одного пациента с недостаточным ответом на лечение метотрексатом. При этом выбор в/в формы абатацепта по сравнению с другими ГИБП (кроме этанерцепта) позволит пролечить в течение 3-х лет от 40 до 80 пациентов в дополнение к 100 пациентам.

В ходе «анализа минимизации» затрат было продемонстрировано, что из расчета на 3 года терапии одного пациента с РА применение п/к формы абатацепта по сравнению с адалимумабом, инфрликсимабом, тоцилизумабом, голимумабом и цертолизумабом пэгол обеспечит экономию денежных средств в размере 380,9 тыс. руб., 697 тыс. руб., 954 тыс. руб., 600 тыс. руб. и 178 тыс. руб., соответственно. В рамках установленного бюджета данная экономия денежных средств позволяет про-

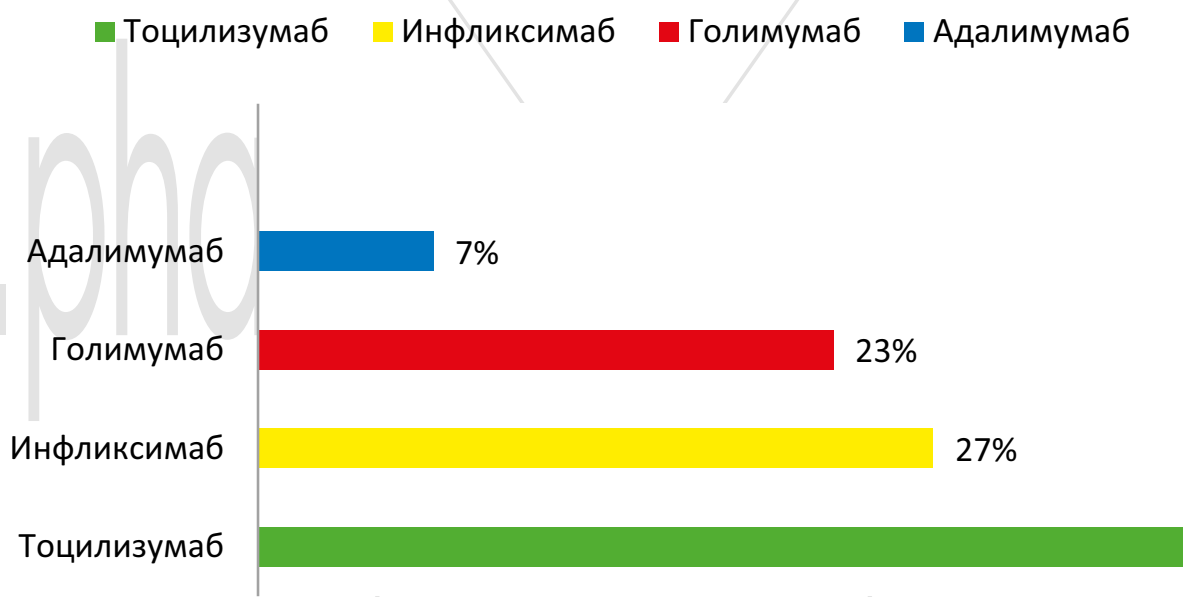

Рисунок 6. Результаты анализа чувствительности при переходе с альтернативных ГИБП на абатацепт п/к

\author{
- Тоцилизумаб \\ Адалимумаб
}
Инфликсимаб
п Голимумаб
- Цертолизумаба пэгол

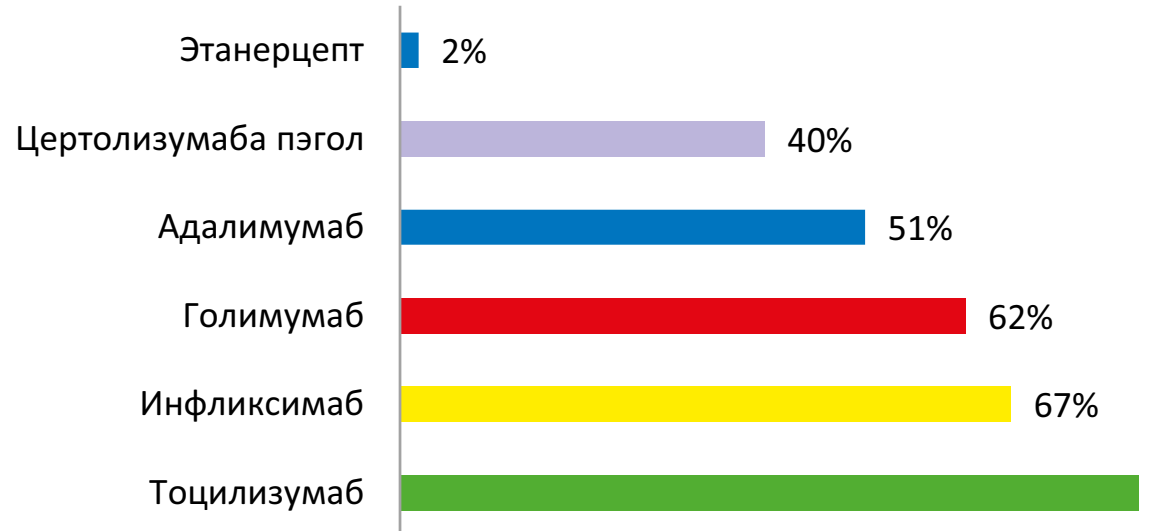

Рисунок 7. Результаты анализа чувствительности при переходе с альтернативных ГИБП на абатацепт в/в 
лечить дополнительных пациентов. В частности, применение п/к фрормы абатацепта по сравнению с вышеуказанными ГИБП позволит в течение 3-х лет обеспечить терапией РА от 7 до 37 пациентов в дополнение к 100 пациентам.

Таким образом, лечение абатацептом в/в и п/к формы можно считать целесообразным у пациентов с выявленной недостаточной эффрективностью терапии МТ с точки зрения фармакоэкономического анализа.

\section{Литература}

1. Балабанова Р. М., Шекшина Е. В. Ревматоидный артрит: новые подходы к старой проблеме //Приложение к журналу «Здоровье. - 2005. - Т. 6. - №. 2526. - С. 18.

2. Балабанова Р.М., Эрдес Ш.Ф. Ревматические заболевания у взрослого населения в федеральных округах России // Научно-практическая ревматология. 2014. № 52. С. 5-7.

3. Зинчук А. Ю. Социальное бремя ревматоидного артрита//Научно-практическая ревматология. - 2014. - Т. 52. - №. 3. - С. 331-335.

4. Каратеев Д. Е. Современная медикаментозная терапия ревматоидного артрита //Леч. врач. - 2007. - Т. 2. - С. 40-6

5. Каратеев Д. Е. Ритуксимаб в современной терапии ревматоидного артрита //Фарматека. - 2010. - №. 5. - С. 26-32

6. Куликов А. Ю. Теоретические основы фармакоэкономического и фрармакоэпидемиологического анализа в системе обеспечения необходимыми лекарственными средствами отдельных категорий населения Российской Федерации //Сборник научных трудов «Разработка, исследование маркетинг новой фармацевтической продукции. - 2008. - №. 63. - С 605-606.

7. Лечение ревматоидного артрита. Клинические рекомендации. Под редакцией Е.Л.Насонова. Издательство «Алмаз», Москва, 2006, 118 стр.

8. Олюнин Ю. А., Каратеев Д. Е. Новые классификационные критерии ревматоидного артрита ACR/EULAR 2010-шаг вперед к ранней диагностике //Научно-практическая ревматология. - 2011. - №. 1.

9. Ревматология: Клинические рекомендации. Под редакцией Е.Л. Насонова. М.: ГЭОТАР-Медиа, 2010.

10. Федеральные рекомендации по лечению пациентов с ревматоидным артритом. Под ред. Е.Л. Насонова. М.:ГЭОТАР-Медиа, 2013.

11. Хабриев Р.У., Куликов А.Ю., Аринина Е.Е. Методологические основь фармакоэкономического анализа. М.: Медицина, 2011. $128 \mathrm{c}$.

12. Ягудина Р.И., Серпик В.Г. О возможностях совмещения анализа «влияния на бюджет» и анализа «затраты-эффективность» - создание «3D» фармакоэкономической модели // Фармакоэкономика: теория и практика. - 2014. - Т.2, №3. - С.4-8.

13. Benucci M, Saviola G, Baiardi P, Manfredi M. Cost-effectiveness treatment with Rituximab in patients with rheumatoid arthritis in real life. Rheumatology International 2011;31(11):November.

14. Cimmino MA, Leardini G, Salaffi F, Intorcia M, Bellatreccia A, Dupont D, et al. Assessing the cost-effectiveness of biologic agents for the management of moderate-to-severe rheumatoid arthritis in anti-TNF inadequate responders in Italy: a modelling approach. Clinical and experimental rheumatology 2011;29(4):2011-Aug.

15. Da Silva E. et al. Declining use of orthopedic surgery in patients with rheumatoid arthritis? Results of a long-term, population-based assessment // Arthritis Care \& Research. - 2003. - Vol. 49. - №. 2. - P. 216-220.

16. Drummond M. F. et al. Methods for the economic evaluation of health care programmes. Oxford University Press.-Third edition.- 2005.- P.379.

17. Gabriel SE, Tugwell P, Drummond M. Progress towards an OMERACT-ILAR guideline for economic evaluations in rheumatology. Annals of the Rheumatic Diseases 2002;61(4):2002

18. Janssen KJ, Medic G, Broglio K, Bergman G, Berry S, Sabater FJ et al. Comparing the efficacy and safety of biologics for the treatment of rheumatoid arthritis patients: a network meta-analysis. Value Health. 2012; 15: A439.

19. Jansen J. P., Buckley F., Dejonckheere F.,Ogale S. Comparative efficacy of biologics as monotherapy and in combination with methotrexate on patient reported outcomes (PROs) in rheumatoid arthritis patients with an inadequate response to conventional DMARDs - a systematic review and network metaanalysis. Health and Quality of Life Outcomes 2014, 12:102.

20. Kobelt G, Eberhardt K, Geborek P. TNF inhibitors in the treatment of rheumatoid arthritis in clinical practice: Costs and outcomes in a follow up study of patients with Ra treated with etanercept or infliximab in southern Sweden. Annals of the Rheumatic Diseases 2004;63(1):January.

21. Kobelt G, Lekander I, Lang A, Raffeiner B, Botsios C, Geborek P. Costeffectiveness of etanercept treatment in early active rheumatoid arthritis followed by dose adjustment. International Journal of Technology Assessment in Health Care 2011;27(3): July.

22. Sany J, Cohen JD, Combescure C, Bozonnat MC, Roch-Bras F, Lafon $G$, et al. Medico-economic evaluation of infliximab in rheumatoid arthritis prospective French study of a cohort of 635 patients monitored for two years. Rheumatology (Oxford, England) 2009;48(10):0ct.

23. Schipper LG, Kievit W, den Broeder AA, van der Laar MA, Adang EMM, Fransen J, et al. Treatment strategies aiming at remission in early rheumatoid arthritis patients: Starting with methotrexate monotherapy is cost-effective. Rheumatology 2011;50(7):ker084.

24. Государственный реестр предельных отпускных цен. 2015. URL: http:// grls.rosminzdrav.ru (Дата обращения 1.03. 2015.).

25. Инструкция по медицинскому применению Абатацепта. 2015. URL: http://grls.rosminzdrav.ru (Дата обращения 10.04.2015.).

26. Инструкция по медицинскому применению Инфликсимаба. 2015. URL: http://grls.rosminzdrav.ru (Дата обращения 10.04.2015.).

27. Инструкция по медицинскому применению Тоцилизумаба. 2015. URL: http://grls.rosminzdrav.ru (Дата обращения 10.04.2015.).

28. Инструкция по медицинскому применению Голимумаба. 2015. URL: http://grls.rosminzdrav.ru (Дата обращения 10.04.2015.).

29. Инструкция по медицинскому применению Цертолизумаба пэгол. 2015. URL: http://grls.rosminzdrav.ru (Дата обращения 10.04.2015.)

30. Инструкция по медицинскому применению Адалимумаба. 2015. URL: http://grls.rosminzdrav.ru (Дата обращения 10.04.2015.).

31. Инструкция по медицинскому применению Этанерцепта. 2015. URL: http://grls.rosminzdrav.ru (Дата обращения 10.04.2015.).

32. Потапчик Е.Г., Попович Л.Д. Социально-экономическая эфффективность государственных инвестиций в медицинские технологии (на примере лечения отдельных заболеваний костно-мышечной системы и соединительной ткани) [Текст]: препринт WP8/2013/02 Е.Г. Потапчик, Л.Д. Попович; Нац. исслед. Ун-т «Высшая школа экономики». - М.: Изд. Дом Высшей школы экономики, 2013. - 56 с.

33. Guyot $\mathrm{P}$ et al. Abatacept with methotrexate versus other biologic agents in treatment of patients with active rheumatoid arthritis despite methotrexate: a network meta-analysis. Arthritis Res Ther 2011;13(6):R204.

34. Guyot $P$ et al. Indirect treatment comparison of abatacept with methotrexate versus other biologic agents for active rheumatoid arthritis despite methotrexate therapy in the United kingdom. J Rheumatol 2012 Jun;39(6):1198-206.

35. Распоряжение Правительства РФ от 26 декабря 2015 г. № 2724-р <0б утверждении перечня жизненно необходимых и важнейших лекарственных препаратов на 2016 год, а также перечней лекарственных препаратов для медицинского применения и минимального ассортимента лекарственных препаратов, необходимых для оказания медицинской помощи 36. Choy EHS, Panayi GS. Cytokine pathways and joint inflammation in rheumatoid arthritis. N Engl, J Med 2001; 344:907-16. 